\title{
Preliminary Tests on a Wireless Sensor Network for Pervasive Dust Moni- toring in Construction Sites
}

\author{
B. Naticchia ${ }^{\mathrm{a}}$, G. Fava ${ }^{\mathrm{b}}$, A. Carbonari ${ }^{\mathrm{a},{ }^{*}}$ and E. Quaquero ${ }^{\mathrm{c}}$ \\ ${ }^{a}$ Department of Civil and Building Engineering and Architecture (DICEA), Università Politecnica delle Marche, via \\ Brecce Bianche, 60131 Ancona, Italy \\ ${ }^{b}$ Department of Materials, Environmental Sciences and Urban Planning (SIMAU), Università Politecnica delle Marche, \\ via Brecce Bianche, 60131 Ancona, Italy \\ ${ }^{c}$ Department of Civil Engineering, Environment and Architecture (DICAAR), Università di Cagliari, via Marengo, 2 \\ 09100 Cagliari, Italy
}

\begin{abstract}
One of the critical aspects in health and safety is the control of fine particle emissions from demolition and construction activities. Such exposure is very often the cause of professional illnesses causing a relevant economic burden for welfare and insurance institutions, besides harming workers. Hence this paper performs a feasibility study of a realtime control system of fine particle concentration on construction sites. It was conceived as a Zigbee ${ }^{\mathrm{TM}}$ based wireless, pervasive and non-invasive system, which is easy to deploy over the site and relatively cheap. Dust sensors were interfaced with the system and calibrated in the laboratory. The prototype is described in detail and tested under controlled and real conditions, in order to determine its potential for application. The prototype was shown to be an excellent tool to support health and safety inspectors, to provide in real-time a broad map of dust concentration over the whole extension of the site, provided that calibration coefficients are worked out for the various types of dust which can be encountered on the site.
\end{abstract}

Keywords: Construction sites, dust sensors, environmental risk, real-time control.

\section{INTRODUCTION}

Fine particle emissions from demolition and construction activities are now recognised as significant causes of pollution and health problems [1]. They are known as $\mathrm{PM}_{10}$, and can cause health hazards both to workers on the site and to people living and working outside the site boundary in the local neighbourhood. $\mathrm{PM}_{10}$ is the finer fraction of "dust" emitted by construction activities, which can easily be carried in the air and penetrate further in the airways, causing well-recognised health problems.

For this reason, national legislation and regulations specify both admissible concentration values in the outdoor environment (i.e. concerning any person) and admissible concentration values in workplaces (i.e. concerning only the workers involved). The legislation relating to health and the environment mostly defines admissible ambient dust concentration as a running 24-hour mean, e.g. both the World Health Organisation [2] and the UK Air Quality Strategy, under Part

*Address correspondence to this author at the Department of Civil and Building Engineering and Architecture (DICEA), Università Politecnica delle Marche, via Brecce Bianche, 60131 Ancona, Italy;

Tel. +39 0712204397; Fax: +39 0712204582;

E-mail: alessandro.carbonari@univpm.it
IV of the Environmental Act [3] define a target $\mathrm{PM}_{10}$ value equal to $50 \mu \mathrm{g} / \mathrm{m}^{3}$. A similar approach has been adopted by the USA in the recent past. The Clean Air Amendment dated 1990 - incorporated into Title 42, Chapter 85 of the United States Code - regulates emissions from any facility into the air. The National Ambient Air Quality Standards (NAAQS) specify dust admissible in the outdoor air as a twenty-four hour average $\mathrm{PM}_{10}$. It must not exceed $150 \mu \mathrm{g} / \mathrm{m}^{3}$, whereas its annual average must not exceed $50 \mu \mathrm{g} / \mathrm{m}^{3}$ [4]. In addition, some US states have had the opportunity to impose stricter limits than those in the NAAQS, e.g. in California the 24-hr average for $\mathrm{PM}_{10}$ was cut down to $50 \mu \mathrm{g} / \mathrm{m}^{3}$ while its yearly mean was limited to $30 \mu \mathrm{g} / \mathrm{m}^{3}$ [5]. Such legislation is also present in other countries: e.g. ambient air quality in Italy is ruled by Legislative Decree no. 52/2006 and is based on similar prescriptions. On the other hand, regulations relating to occupational exposure define limit values in terms of a Time Weighted Average (in short called TWA) of total dust concentration over the $8 \mathrm{~h}$ working day, whose thresholds differ slightly depending on the country. In addition, the aforementioned body of laws states that, besides limiting dust concentration within construction sites, emissions outside the site must be kept low.

In the construction field, $\mathrm{PM}_{10}$ is originated by several concurrent factors, determined on the one hand by the site 
layout and organisation and, on the other, by the type of demolition or construction activities in progress. Dust and mud from roads and haulage routes on the site can become airborne through the movement of vehicles. Vehicles and some plants also generate engine exhaust emissions. In addition, the handling and storage of fine, powdery and dry materials has the potential for making the dust airborne, e.g. when loading vehicles and conveying materials through chutes down into skips. Similarly, dust from demolition is very likely to spread into neighbouring areas. A number of fabrication processes are major sources of airborne particles, among which we cite operations such as cutting, grinding, sand-blasting, drilling and disk cutting. In literature, several contributions have shown that, at times, workers are exposed to dust concentrations far higher than the $24 \mathrm{hr}$ running ambient admissible value [6], and several times higher than the admissible value in workplaces.

Recommended control measures are those which reduce dust generated at its source [1]. Pre-project risk assessment is able to identify risks and mitigation actions, but cannot quantify their real effectiveness, which is strongly dependent on operational approaches, unless monitoring techniques are used. So far two main monitoring methods have been employed, according to relevant regulations [7]:

- $\quad$ pumped samplers that collect particles on a filter for later weighing or chemical analyses (generally held on site for some days or weeks), which is known as the gravimetric approach;

- continuous sampling instruments to provide fast online plots of dust concentration (e.g. light scattering), thanks to the use of optical instruments.

The work presented in our paper has the purpose of contributing to the second approach, by means of an advanced and non-invasive wireless sensor network, which is able to provide pervasive and continuous monitoring of the presence of dust on site. In fact, currently used sampling instruments are quite expensive, need to be connected to the power line and are of considerable size, so just a few of them can be deployed in work places. The availability of miniaturized long-life battery powered sensors would enhance dust tracking opportunities. More specifically, the continuous monitoring approach could be used to promptly warn health and safety inspectors in case some admissible thresholds are overcome. However, even considering the unpredictable position of dust sources in construction sites (which are often free to move around), monitoring must also be pervasive, i.e. capable of covering the whole site area. As a consequence, a number of sensors must be scattered, which is feasible just in case they are cheap and easy to deploy, so that also manpower for their relocation will be cheap. For that reason, we attempted to find a specific technology which could meet such requirements, with particular reference to: low cost, ease of installation and deployment throughout the site, unobtrusiveness with respect to construction tasks in progress, real-time communication of sensed values towards a central hub and reliability, which was evaluated with reference to current high quality measurement systems.
Feasibility analyses and a discussion about the applicability of this solution in the construction industry will be presented. This new system was conceived so as to be able to provide a broad spatial distribution of dust concentration close to sensitive receptors on the site. Once dust concentration is known in those critical areas where sensors are located, the spatial distribution of dust all over the whole construction site can be estimated by means of known diffusion models [8]. In this research step we focused on the need for the presence of a sensor set, capable of tracking dust concentration in real-time, which is critical for obtaining a reliable picture of spatial dust distribution. As a result, once cheap, easy to deploy and pervasive sensor networks are available, they should determine several benefits, such as:

- triggering of warnings, when dust values exceed predetermined thresholds;

- $\quad$ reduction in the number of environmental offences and hence in prosecutions by local authorities, which is a relevant financial burden for builders [9];

- reduction in the site engineer's workload;

- reduction in the health damage to the workers.

The last issue is of utmost importance, as shown by available statistics. In fact, despite the use of personal protective equipment, workers are still prone to the development of serious illnesses. In the construction industry, silicosis is caused by the inhalation of crystalline silica dust. A study conducted in the U.S. shows that approximately 2,000,000 workers are exposed to crystalline silica and 100,000 of them face related risks. For this reason, in 1995 the OSHA Priority Planning Process included the fight against silica among its priorities and, since 1997, when the IARC re-classification put crystalline silica among those classified as carcinogens, OSHA has set up a strong initiative against the risk of silicosis [10]. A similar approach was adopted by the ILO/WHO International Programme published in 1995, which placed, as a short-term goal, the promotion of national programs to reduce the incidence of silicosis by 2010 and, in the long term, the cancellation of silicosis from the list of occupational diseases by 2030 .

Another meaningful example is given by the reports on silicosis published by the Italian Institute for Insurance of accidents at work (usually referred to as "INAIL"). These reports showed that insurance premiums compensating for silicosis and related diseases have increased. In particular, a $6.9 \%$ increment in respiratory diseases was registered in the year from 2010 to 2011 [11]. Hence the 81/2008 Legislative Decree by the Italian government included research related to silicosis among the projects to be funded by INAIL with the wider aim of increasing health and safety at work. This shows how critical the issue is considered by the experts in the field and the urgent need for the continuous control of air quality on construction sites.

In the next Section 2 we describe our system and its basic features. The following Section 3 reports on the calibration trials and simulations of on-field measurements. Section 4 discusses the results obtained in the previous section and, finally, our conclusions and acknowledgments are presented. 


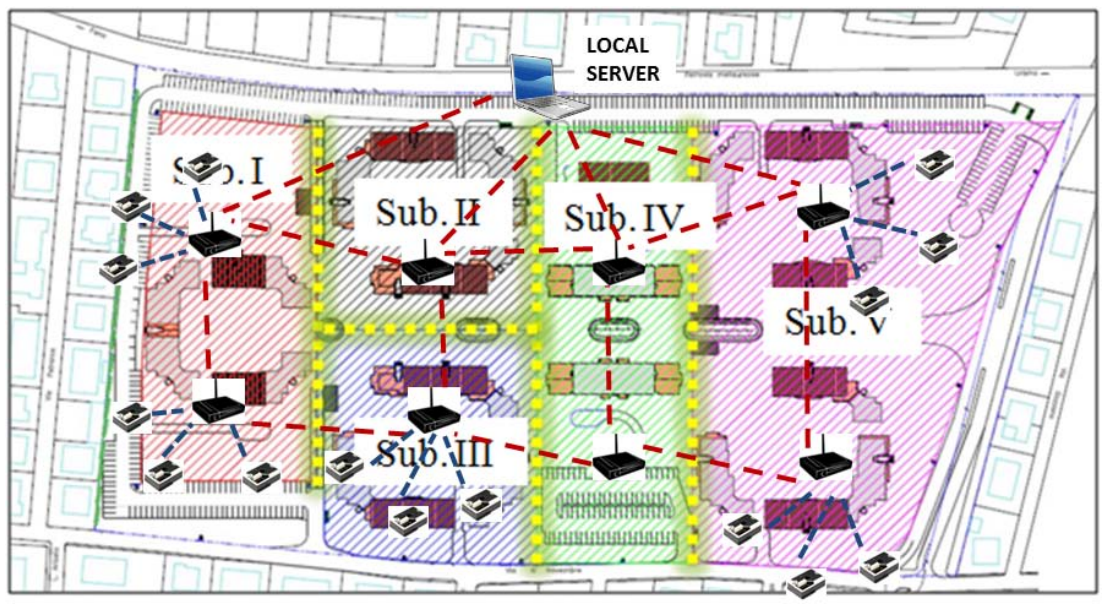

Fig. (1). Schematic pervasive deployment of the wireless communication system over a typical construction site.

\section{SYSTEM FOR PERVASIVE MONITORING OF DUST}

The dust tracking system we present adopts advanced computing and sensor network technologies for automatic wireless data acquisition and communication [12]. It is based on and exploits the benefits from the $\mathrm{ZigBee}{ }^{\mathrm{TM}}$ standard. The same radio hardware can be used for both localisation and communication. In addition, the quite long communication range between devices and the possibility to form dynamic mesh communication networks make this technology really powerful and suitable for covering large working areas. These mesh networks are also capable of reconfiguring should any sensor be relocated when the site layout is rearranged.

Thanks to the selected communication technology, and the availability of such low cost, non-invasive, easily deployable wireless communication networks, continuous $\mathrm{PM}_{10}$ concentration tracking is made feasible. Fig. (1) represents the concept of "pervasive" tracking, where dust sensors are opportunely deployed over the site area, in order to perform the continuous and on-line tracking of dust concentration throughout the construction site. The adoption of such a system would offer the opportunity to assess in real-time the effectiveness of the safety procedures adopted for dust suppression and real-time control in sub-areas where the sensitive receptors are operating.

The importance of pervasive and on-line tracking of resources and materials on construction sites has already been discussed by other authors and its benefits shown for different fields. Among them we cite: material management and inventory traceability can cancel inefficiencies currently generated by manually tracking materials [13]; automated progress monitoring reduces the burden of work usually required to edit project reports [14]; automated waste management is aimed at reducing the non-recycled fraction and at cutting down the environmental impact [15]. The importance of tracking for improved health and safety management has also been stressed by a number of relevant contributions [16-18].

Currently, to the best of the authors' knowledge, no contributions about the development of a wireless and easy to deploy tracking system, customized for the purpose of fine particle dust monitoring on construction sites, have been published. However, it is well known that such a system would be necessary in order to assess the expected impact of dust emissions from construction into the surrounding environments. Although relevant advances have been made in the field of wireless communication, as mentioned above, yet the development of cheap and miniaturized sensors (i.e. end devices) to be integrated within wireless communication networks remains urgent. Therefore the next two sub-sections will report the technical features of a first prototype of dust monitoring end device, whose performances were tested as described in the rest of the paper.

\subsection{The Communication System}

The wireless communication network is based on the SmartNetwork Platform, an ultra-low power wireless technology (manufactured by Smart Space Solutions srl). It is capable of tracking large areas with a wireless mesh network architecture, made up of battery operated devices. The SmartNetwork includes three levels of devices: one or more coordinators, routers and sensors.

Routers forward messages across the network devices, they support up to 65,000 nodes structured under the form of a mesh network and can provide self-healing capabilities and self-configuration. Thus routers make it feasible to broadcast and exchange messages throughout the network, besides providing backup routes in case of network overloading or failure of one or more devices.

Interaction among the three levels of devices makes the overall communication possible (Fig. 2). Network formation and configuration is made possible by one PAN coordinator per each unit of the communication network; when the route of any message between an end device and the coordinator takes advantage of more than one router, it is called multihop routing; end devices (also called "reduced function devices-RFD") act as multi-purpose sensors and do not have routing capabilities.

This communication network is characterized by low installation costs, because, even though it is battery powered, it can work for years without battery replacement. That is 
made possible by the implementation of a special hardware and firmware architecture, which keeps the communication device in "sleep" mode for most of the time and wakes it up just in case one message need to be routed, by means of an extremely low power RF wakeup impulse (whose peak power is no higher than $0.05 \mathrm{~mW}$ ). Once the appropriate nodes of the network are awakened, the transmission is performed through the network using the primary radio system which returns to sleep mode when no data need to be transferred. This technology allows a long timespan between two consecutive battery replacements, usually in the order of a few years, and was already successfully tested in large construction sites for real-time communication [19].

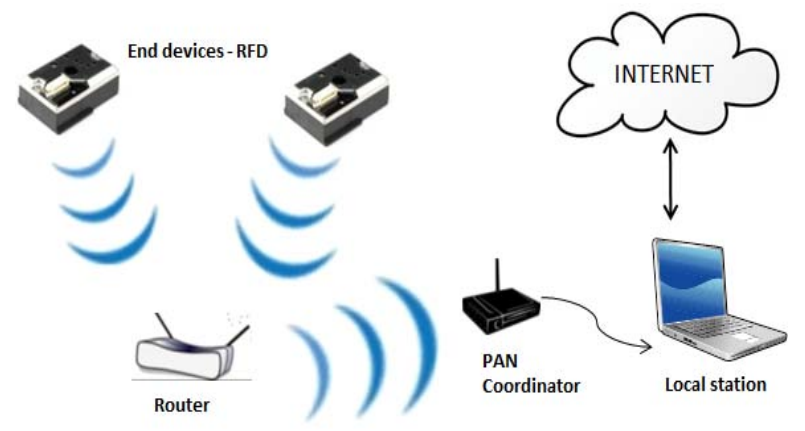

Fig. (2). Layered structure of the wireless communication network used for dust tracking.

\subsection{Dust Sensors}

A nephelometer sensor, whose features are listed in Table 1, manufactured by Sharp Inc. was embedded in the RFDs (sensor code: GP2Y1010AU0F). All the electronic equipment, including a tilt sensor and the hardware for communication, was contained in a water tight plastic box by $\mathrm{Ge}-$ wiss $^{\text {TM }}$. This sensor works based on the optical principle, and it does not affect the power consumption of the whole device, because the maximum current request does not exceed $20 \mathrm{~mA}$. Technically, an air flow stream is passively conveyed through a measurement chamber, where a light beam is emitted and the ratio of light scattered by $\mathrm{PM}_{10}$ is detected [20]. Present applications of this sensor include its use as a probe for air quality measurement in air purifiers. It is a cheap, small, low-power tool. At each acquisition, the Sharp dust sensor's measurement chamber causes a pulse whose voltage is proportional to the number of particles which cause the light beam to be diffracted $\left(\mathrm{V}_{\mathrm{s}, \mathrm{i}}\right)$.

The microprocessor works out the mean based on the last 16 records:

$V_{s}=\frac{!_{i=1}^{16} V_{s, i}}{16}$

$\mathrm{V}_{\mathrm{s}}$ is then converted (ADC) into an integer number (L) with 10 bit resolution $(\mathrm{R}=10)$ by an Analog to Digital Converter. It is interfaced to a PIC 24F32KA302 microprocessor (Fig. 3). The ADC uses a $1.8 \mathrm{~V}$ reference voltage $\left(\mathrm{V}_{\text {ref }}\right)$. A voltage divider is installed before the ADC to avoid its saturation for $V_{s}$ greater than the reference voltage $V_{\text {ref. There- }}$ fore the integer number $(\mathrm{L})$ converted by the microprocessor is given by:

$$
L=\frac{1}{2} ! V_{s} ! \frac{\left(2^{R} 1\right)}{V_{r e f}}
$$

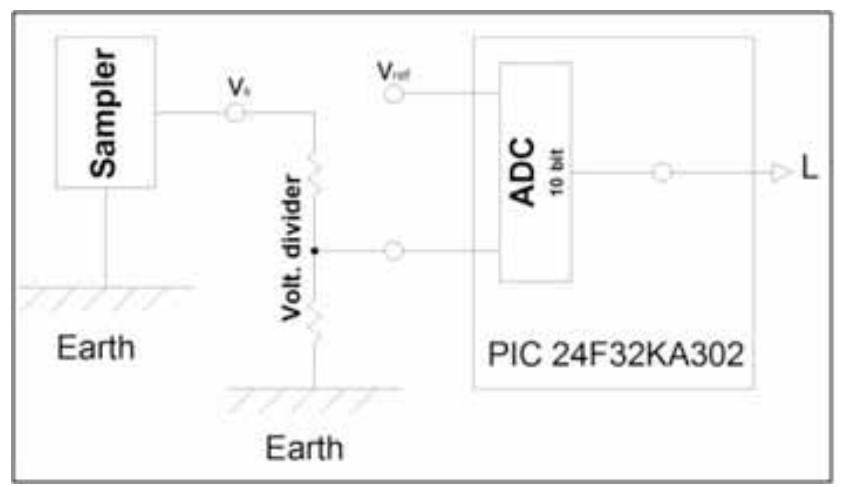

Fig. (3). Dust sensor electronic schema.

Table 1. Main parameters of the Sharp dust sensor.

\begin{tabular}{|c|c|c|c|}
\hline Parameter & Units & Typical Value & Constraints \\
\hline \hline Supply Voltage & $\mathrm{V}$ & -0.3 to +7 & $\mathrm{~T}_{\mathrm{a}}=25^{\circ} \mathrm{C}$ \\
Operating temperature & ${ }^{\circ} \mathrm{C}$ & -10 to +65 & - \\
Sensitivity & & 0.5 & $\mathrm{~T}_{\mathrm{a}}=25^{\circ} \mathrm{C} ;$ \\
& & & $\mathrm{V}_{\mathrm{cc}}=5 \mathrm{~V}$ \\
Output voltage at no dust & $\mathrm{V} /\left(0.1 \mathrm{mg} / \mathrm{m}^{3}\right)$ & 0.9 & $\mathrm{~T}_{\mathrm{a}}=25^{\circ} \mathrm{C} ;$ \\
& & $\mathrm{V}$ & $\mathrm{V}_{\mathrm{cc}}=5 \mathrm{~V}$ \\
Consumption current & $\mathrm{V}$ & 11 & $\mathrm{~T}_{\mathrm{a}}=25^{\circ} \mathrm{C} ;$ \\
\end{tabular}




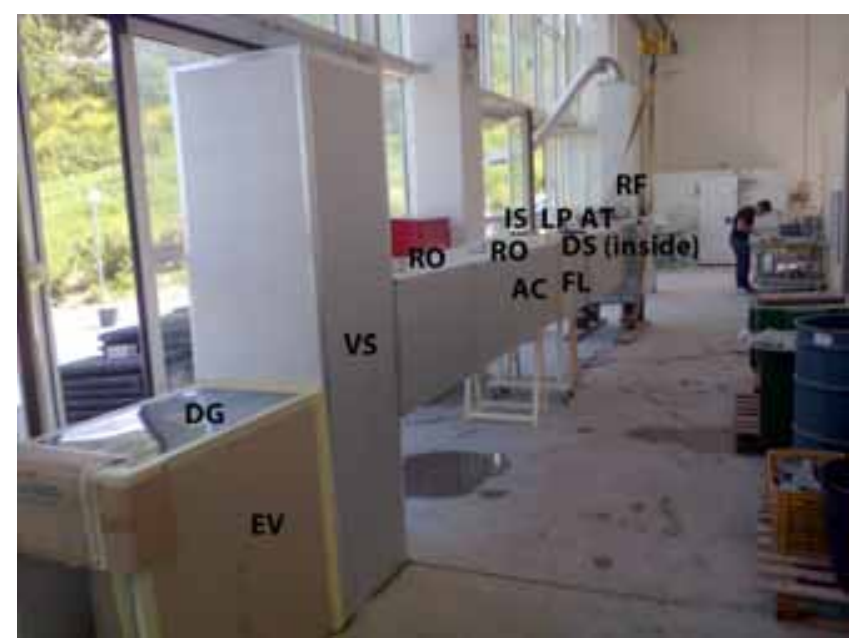

Fig. (4). Dust ventilation duct with measuring instruments.

\section{EXPERIMENTAL CAMPAIGN}

\subsection{Overview of the Experimental Campaign}

Two phases contributed to our experimental campaign. In the first one, sensor calibration under controlled conditions was performed. The new system was calibrated against the measurements of a highly accurate sensor, which was used as a benchmark. In the following phase, a few activities typically performed on construction sites were simulated in our laboratory. Thus, the system's ability to detect relevant events, responsible for dust generation, was assessed.

\subsection{Experimental Trials for Sensor Calibration}

The system's characterisation and calibration was performed in the concrete laboratory of the Simau Department at the Università Politecnica delle Marche, under controlled conditions in order to avoid bias by unknown factors. A dust ventilation duct was set up in order to place the sensors and control the physical variables during testing (Fig. 4). The 10 $\mathrm{m}$ long duct had a cross section measuring $0.7 \mathrm{~m}$ by $0.7 \mathrm{~m}$ and was made of high insulated aluminium coated casing (AC), connected to a vertical substructure (VS) with a grid (at the intersection between the two) for homogenising the inlet generation. Sea salt dust generation (DG) was provided by means of an ultrasonic fog generator placed at the inlet of the dust ventilation duct. The ultrasonic fog generator uses ultrasonic technology to produce a fog composed of $10 \mu \mathrm{m}$ and less sized water particles which gives smaller solid particle diameter as determined by eqs. (3) and (4) [21]:

$$
\begin{aligned}
& D_{g}=0.34 \frac{\& 8\left(T_{w}\right.}{q d_{w} f^{2}} !^{\frac{1}{3}} \\
& D_{P}=D_{g} \cdot\left(\frac{C_{w}}{d s} \cdot 10^{6}\right)^{\frac{1}{3}}
\end{aligned}
$$

where $D_{g}$ is the fog drop diameter, $D_{p}$ is the solid particle diameter, $d_{w}$ is water density, $T_{w}$ is surface tension (dine $/ \mathrm{cm}^{2}$ ), $\mathrm{f}$ is the ultrasonic frequency $(\mathrm{MHz}), \mathrm{C}_{\mathrm{w}}$ the solute concentration $(\mathrm{g} / \mathrm{L})$ and $\mathrm{d}_{\mathrm{s}}$ the solute density $(\mathrm{g} / \mathrm{L})$.

Generation was protected by an envelope (EV) to avoid ambient disturbances. A filter (FL) along the duct guaranteed diffusion of the generated dust. The dust sensors (DS) were placed downstream inside the duct and the coordinator (not shown in Fig. 4) inside the laboratory was connected to a laptop. In between, two routers (RO) transferred the acquired data. Three active techniques were used for comparison. The first involved one IOM inhalable dust sampler (IS) suctioning a $2 \mathrm{l} / \mathrm{min}$ constant volume flow through a small pipe whose loose end was placed close to the dust sensors. It operates with a flow that is able to conserve isokinetic conditions during sampling. The second one used an optical particle counter Grimm 1.108, which is a portable laser photometer (LP) with a constant volume flow of $0.61 / \mathrm{min}$ and a digital display for real-time measurement. Finally, a removable $47 \mathrm{~mm}$ PTFE filter was incorporated inside the instrument in order to collect all the measured dust, so that, at any later time, an appropriate density verification/correction would be possible. This filter is in accordance with many national and ISO standards. The air flow rate inside the dust ventilation duct was generated by the rotating fan (RF) and its amount estimated by means of an anemometer type "TestoModel445" (AT), equipped with a hot bulb NTC probe whose range spans between 0 and $5 \mathrm{~m} / \mathrm{s}$ and whose accuracy is $0.01 \mathrm{~m} / \mathrm{s}$. The operating temperature was well within the limits imposed by the instrument (i.e. between -20 and $70^{\circ} \mathrm{C}$ ). The dust sensors, the IOM sampler and the Grimm sampler were all placed on the same section of the duct, thus making them suction air at the same point along its path.

Calibration lasted 53 minutes, and during that time fine particle dust, whose diameter ranged between 0.23 and 10 $\mu \mathrm{m}$, was generated. The air speed was kept constant at 0.45 $\mathrm{m} / \mathrm{s}$. The benchmark recorded one measurement every minute, while the two passive samplers recorded one measurement every $10 \mathrm{~s}$ according to eqs. (1) and (2). Subsequently, post-processing worked out the average values per minute, in order to be able to compare the two datasets, as in (Fig. 5).

This figure shows a good agreement between the two passive samplers and the benchmark (i.e. Grimm). The average dust concentration experienced during this trial (worked out by IOM) was $2.077 \cdot 10^{3} \mu \mathrm{g} / \mathrm{m}^{3}$, although the increasing trend at the beginning was determined by the time needed for the generated dust to spread across the dust ventilation duct.

\subsection{Simulation of On-field Measurements}

In the same laboratory two more series of on-field simulation measurements were carried out. They were supposed to simulate real on-field monitoring, similar to the type expected to be carried out on construction sites. The two series differed as follows:

- the first one simulated a typical construction activity, the weighing and mixing of concrete with granular materials (carried out on May $13^{\text {th }} 2013$ ); 


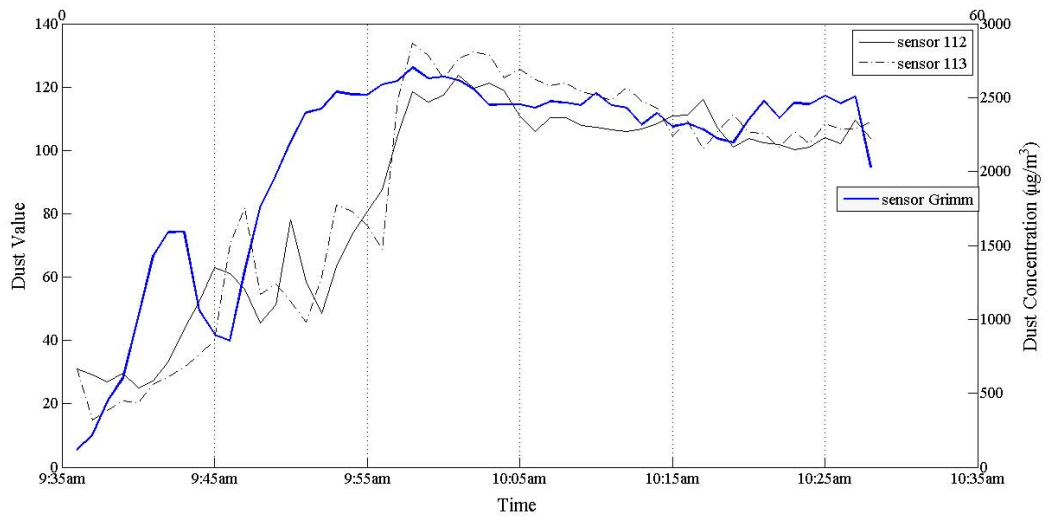

Fig. (5). Plots of estimated dust concentration by the three sensors during laboratory tests.

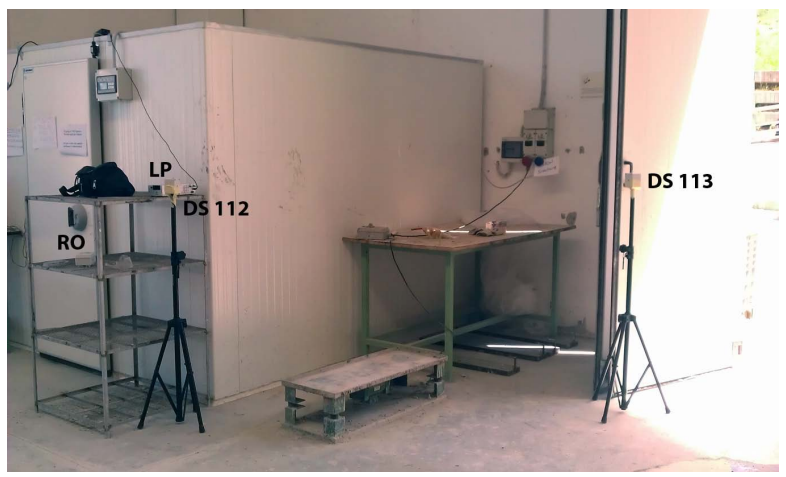

(a)

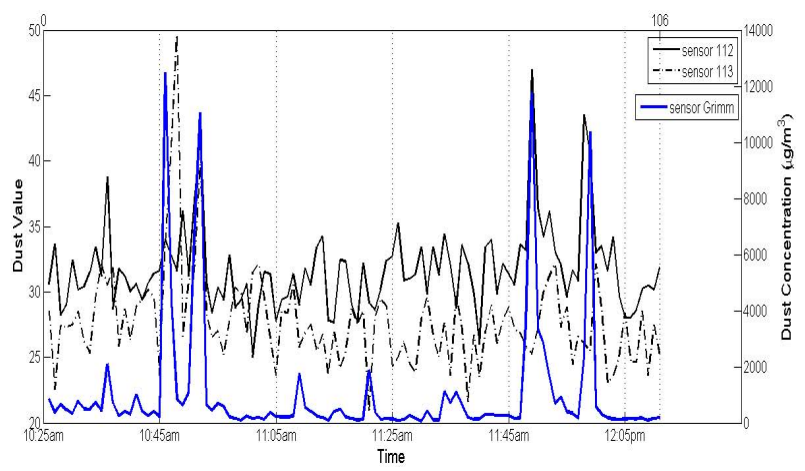

(b)

Fig. (6). Deployment of sensors during the first simulation of on-field measurements (a) and plots of the corresponding data (b).

- the second one compared the behaviour of the two passive sensors, when placed in different locations: one outdoors and the other one indoors, with the latter being coupled to the benchmark sensor (i.e. Grimm), while the laboratory staff were mixing and pouring concrete into formworks for the production of cubic concrete specimens (dated May $14^{\text {th }} 2013$ ).

In (Fig. 6-a) the positions of the sensors during the first set of measurements are shown. The two passive dust sensors (DS no. 112 and 113) were placed close to the weighing equipment on which the concrete was mixed and then poured into formworks. The Grimm laser photometer (LP) was kept next to sensor 112, in order to get benchmark values over the whole measurement period. All the sensors were located at the top of $1.6 \mathrm{~m}$ high supports (i.e. the passive sensors on two tripods and the Grimm on a shelf). In this case the experiments were not carried out under controlled conditions and the layout was more similar to a real work place, where environmental conditions are highly changeable and hard to predict. The two routers (of which only one is visible in the photo - RO) were responsible for routing messages to the PAN coordinator and the local station, which was kept at a safe distance from the source of dust.

A comparison between the plots deriving from the different sensor acquisitions is depicted in (Fig. 6b). The plots of sensor 112 and the benchmark have remarkably similar peaks, even though they differ in case of low dust density, probably because the Sharp devices are affected by electronic noise. Values relative to sensor 113 are lower on the average, and a summary is reported in Table $\mathbf{2}$.

The second series of experiments had a different objective: not only did it compare one passive sensor with the benchmark, but also the two passive sensors were located far apart (Figs. 7a and 7b):

- dust sensor 113 was placed outdoors, far enough from the laboratory so as not to interfere with the dust flow generated therein and carried by the wind;

- dust sensor 112 was placed in the laboratory and close to the benchmark.

Table 2. Typical values of the measurements collected by the passive sensors during the three tests.

\begin{tabular}{|c|c|c|c|c|}
\hline \hline Sensor no. & Measurem. Series & Min & Mean & Max \\
\hline \hline 112 & controlled & 25 & 86.0 & 123.8 \\
113 & controlled & 15 & 86.4 & 133.8 \\
\hline 112 & $1^{\text {st }}$ on-field & 25 & 31.7 & 47 \\
113 & $1^{\text {st }}$ on-field & 20.8 & 27.7 & 49.7 \\
112 (indoor) & $2^{\text {nd }}$ on-field & 26.6 & 41.4 & 207.3 \\
113 (outdoor) & $2^{\text {nd }}$ on-field & 29.9 & 29.9 & 49.8 \\
\hline \multicolumn{4}{|r}{}
\end{tabular}




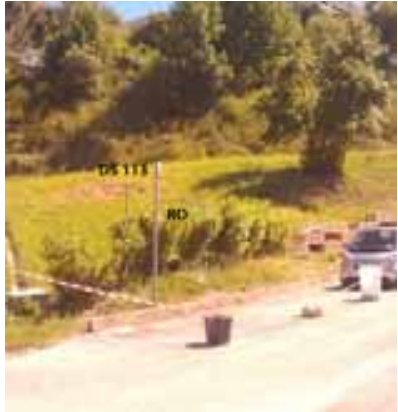

(a)

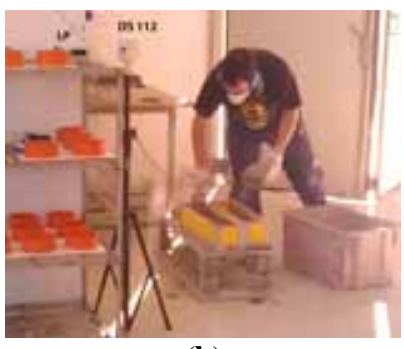

(b)

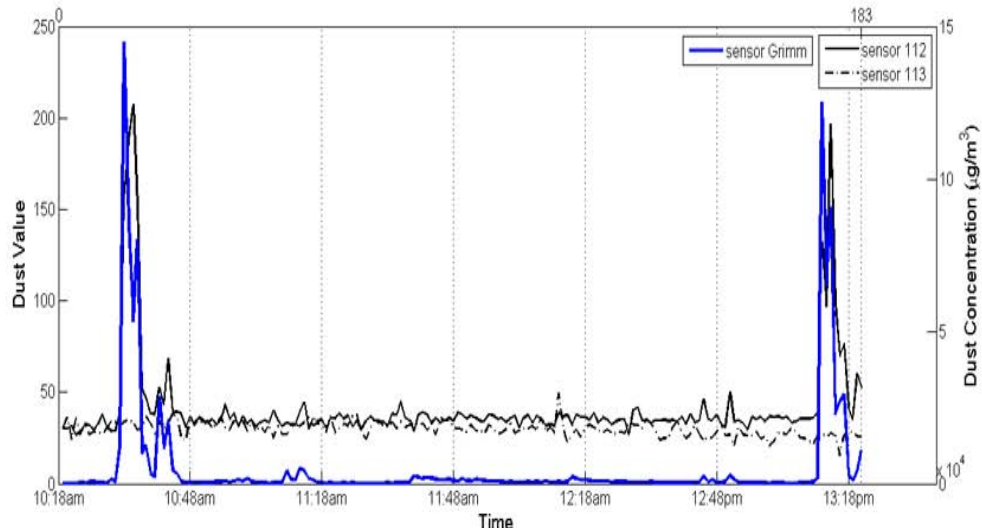

(c)

Fig. (7). Location of sensor 113 outdoors (a), of sensor 112 indoors close to the Grimm sensor (b) and plots of the relative data (c).

Thus, this trial added further information to the previous simulation: firstly, it compared the behaviour of the two sensors when placed in two environments with different background dust levels; secondly, it helped calibrate one of the dust sensors, while another specific construction activity was taking place, namely concrete pouring into formworks. The entries in Table 2 relative to this second trial clearly show that sensor 112 is triggered by two main events (represented by the peaks in Fig. 7c), which are responsible for the high average concentration measured by the benchmark. On the contrary, the measurements for sensor 113 are located around its average value at rest, and the sensor is activated by many low intense events taking place outdoors.

\section{DISCUSSION}

Given the experiments we have performed so far, we can make several remarks about the features of the two passive sensors.

Firstly and from the qualitative point of view, the plots of all the passive sensors match that one of the benchmark, especially when peaks are experienced and if they are placed side by side. Moreover, the two passive sensors appear to be very reliable, as they behaved in a consistent way.

Secondly, (Fig. 5) shows that above the threshold given by $500 \mu \mathrm{g} / \mathrm{m}^{3}$, the two passive sensors present similar swings to the benchmark, and they also stabilise on the same plateau in the second part of the diagram, that is, once the dust reaches a uniform concentration value inside the duct. This means that the passive sensors are well capable of signalling when the $\mathrm{PM}_{10}$ is above the recommended threshold in workplaces, which is always in the order of a few $\mathrm{mg} / \mathrm{m}^{3}$.
The two series of conversion factors computed after the three trials and shown in Table $\mathbf{3}$, each relative to a different type of activity and dust generated (i.e. controlled conditions and on-field like experiments), may be considered as a preliminary set of data of an expert system, which is able to convert digital measurements into dust concentration. In fact, they are worked out as the ratio between the average dust concentration measured by the benchmark during the tests and the average value sensed by the passive sensors over the same time lag. In other words, the development of a set of conversion factors for the types of dust typical of construction sites and type of measurement taking place should provide the necessary knowledge to be able to make a rough estimation of $\mathrm{PM}_{10}$ concentration from the real-time measurements provided by the system. In this way, the system would be capable of warning health and safety inspectors when pre-determined thresholds are likely to be exceeded.

In addition, the good matching between the conversion factors of the two sensors in the first trial (when the sensors were kept in the same condition) shows the repeatability and usability of this prototype for the purpose. On the contrary, only one conversion factor was computed for the second series of experiments, because in the second part of the onfield like tests sensor 113 was located outdoors, and hence could not be compared with the benchmark, which was indoors.

\section{CONCLUSION}

In this paper we have analysed the feasibility dust monitoring end devices to be integrated within a wireless and non-invasive dust monitoring network for construction sites. The main challenges offered by this kind of environment are 
Table 3. Conversion factors from the readings of passive sensors for dust concentration.

\begin{tabular}{|c|c|c|c|}
\hline & Sensor 112 & Sensor 113 & Grimm \\
\hline \multicolumn{4}{|c|}{ Trial no. 1: under controlled conditions. } \\
\hline Average number & 86.046 & 88.442 & \\
\hline Avr. Conc. $\left(\mu \mathrm{g} / \mathrm{m}^{3}\right)$ & & & $2.077 \cdot 10^{3}$ \\
\hline Conv. factor & 24.14 & 23.48 & \\
\hline \multicolumn{4}{|c|}{ Trial no. 2: first on-field like test. } \\
\hline Average number & 31.71 & 27.74 & \\
\hline Avr. Conc. $\left(\mu \mathrm{g} / \mathrm{m}^{3}\right)$ & & & $2.023 \cdot 10^{3}$ \\
\hline \multicolumn{4}{|c|}{ Trial no. 3: second on-field like test. } \\
\hline Average number & 41.374 & 29.891 & \\
\hline Avr. Conc. $\left(\mu \mathrm{g} / \mathrm{m}^{3}\right)$ & & & $5.291 \cdot 10^{3}$ \\
\hline Conv. factor & 86.4 & N.A. & \\
\hline
\end{tabular}

due to the unpredictable distribution of sensitive receptors throughout the whole working area, the unpredictable schedule of the several concurrent activities taking place, and their influence on the surrounding neighbourhood. Yet dust monitoring in construction sites is critical to protect the surrounding environment. These challenges require the use of pervasive monitoring systems that can be spatially deployed so as to cover all the site extension. In addition, the system must be economically affordable, in case it is held on site for the whole duration of the demolition and construction works.

To that end, we assembled and tested an untethered monitoring setup, made of wireless devices based on the Zigbee $^{\mathrm{TM}}$ communication protocol and mounting a cheap Sharp dust monitoring sensor. The three laboratory tests that were performed under different conditions showed that this system is sensitive enough to signal most of the occurrences of intense dust generation. This means that safety inspectors can be warned by the system when hazards connected to $\mathrm{PM}_{10}$ generation are occurring. As a consequence, safety inspections and more accurate measurements can be planned on purpose and correlations between the types of construction/demolition activities and dust levels may be worked out.

In addition, the pervasive monitoring allowed by this sensor setup would make the monitoring of extended sources of dust feasible. This is not possible through the use of current technologies, which are mainly devoted to point measurements and dust sampling. For this reason, this new setup might be considered as a complementary system to some more accurate measurement approaches which are currently used, and it was specifically designed to solve the particular challenges posed by construction sites.

As its sensitivity varies with the type of dust, further tests will be performed to extract conversion factors and curves allowing digital values to be turned into concentration estimations. Finally, future developments will include the comparative testing of other cheap dust sensors, in order to perform relative performance evaluations.

\section{NOMENCLATURE}

\begin{tabular}{|c|c|c|}
\hline Variable & Meaning & units \\
\hline $\mathrm{PM}_{10}$ & $\begin{array}{c}\text { Particulate matters whose size is no larger } \\
\text { than } 10 \mu \mathrm{m}\end{array}$ & $\mu \mathrm{m} / \mathrm{m}^{3}$ \\
\hline $\mathrm{V}_{\mathrm{s}, \mathrm{i}}$ & $\begin{array}{c}\text { Voltage of the pulse generated by light dif- } \\
\text { fracted in the measurement chamber of } \\
\text { nephelometers. }\end{array}$ & $\mathrm{V}$ \\
\hline $\mathrm{L}$ & $\begin{array}{c}\text { Digital value resulting from analogue to } \\
\text { digital conversion of } \mathrm{V}_{\mathrm{s}, \mathrm{i}}\end{array}$ & - \\
\hline $\mathrm{V}_{\mathrm{ref}}$ & $\begin{array}{c}\text { Reference voltage used for analogue to digi- } \\
\text { tal conversion of } \mathrm{V}_{\mathrm{s}, \mathrm{i}} .\end{array}$ & $\mathrm{V}$ \\
\hline $\mathrm{D}_{\mathrm{f}}$ & Fog drop diameter of generated moist & $\mu \mathrm{m}$ \\
\hline $\mathrm{D}_{\mathrm{p}}$ & Solid particle diameter & $\mu \mathrm{m}$ \\
\hline $\mathrm{d}_{\mathrm{w}}$ & Water density & $\mathrm{kg} / \mathrm{m}^{3}$ \\
\hline $\mathrm{T}_{\mathrm{w}}$ & Surface tension & $\mathrm{dyne} / \mathrm{cm}^{2}$ \\
\hline $\mathrm{F}$ & Ultrasonic frequency & $\mathrm{MHz}$ \\
\hline $\mathrm{C}_{\mathrm{w}}$ & Solute concentration & $\mathrm{g} / \mathrm{L}$ \\
\hline $\mathrm{d}_{\mathrm{s}}$ & Solute density & $\mathrm{g} / \mathrm{L}$ \\
\hline
\end{tabular}

\section{CONFLICT OF INTEREST}

The authors confirm that this article content has no conflict of interest. 


\section{ACKONWLEDGEMENTS}

The authors wish to express their gratitude to Engineers Anael Peroni, Adriano Morresi and Mr. Roberto Mancini, who kindly supported the tests and analyses presented in this paper.

\section{REFERENCES}

[1] V. Kukadia, S. Upton and D. Hall, "Control of dust from construction and demolition activities", Eds. BRE Bookshop, 2003, ISBN: 1860816126.

[2] WHO - The World Health Organization, "Air quality guidelines Global Update 2005". Printed in Germany by Druckpartner Moser, 2006.

[3] Environmental Act Part IV. 1995. The Stationary Office Ltd. ISBN: 0105425958

[4] J.G. Watson, J.C. Chow, D. DuBois, M. Green, N. Frank and M. Pitchford, "Guidance for network design and optimum site exposure for PM2.5 and PM10", Research Triangle Park, NC: U.S. Environmental Protection Agency (E.P.A.), Office of Air Quality Planning and Standards, 1997.

[5] California Air Resources Board, "Ambient air quality standards for particulate matter", 2003.

[http://www.arb.ca.gov/research/aaqs/pm/pm.htm]

[6] K. D. Linch, "Respirable concrete dust-silicosis hazard in the construction industry", J. Occup. Environ. Hyg., vol.17, no. 3, pp. 209221, 2003.

[7] M. E. Flanagan, N. Seixas, M. Majar, J. Camp, and M. Morgan, "Silica dust exposure during selected construction activities", AIHA Journal, vol. 64, pp. 319-328, 2003.

[8] CALPUFF Modelling System. 2013. Available on-line at: www.epa.gov/scram001/dispersion_prefrec.htm [Last access in: June 2013].

[9] R. Sukys, P. Cyras, and J. Sakenaite, "Economical loss due to noncompliance with requirements for personnel safety and health in
Lithuanian construction sector", J. Civ. Eng. Manag., vol. 17, no. 2, pp. 168-176, 2011

[10] R. Haber, "Crystalline Silica: The US Approach" (Extended Abstracts), In: Cristalline Silica and Oncogenesis, Bologna October 24, 2000 .

[11] INAIL Report 2011 - Part IV - Statistical data: occupational diseases - July 2012

[12] W. S. Jang, and J. Skibniewski, "A wireless network system for automated tracking of construction materials on project sites", $J$. Civ. Eng. Manag., vol. 14, no. 1, pp. 11-19, 2008.

[13] L. Weisheng, Q. H. George, and L. Heng, "Scenarios for applying RFID technology in construction project management", Automat. Constr., vol. 20, pp. 101-106, 2011.

[14] R. Navon, and E. Goldschmidt, "Can Labor Inputs be Measured and Controlled Automatically", J. Constr. Eng. M., vol. 129, no. 4, pp. 437-445, 2003

[15] L. Shen, V. Tam, C. Tam, and D. Drew, "Mapping approach for examining waste management on construction sites", J. Constr. Eng. M., vol. 130, no. 4, pp. 472-481, 2004.

[16] L. Ung-Kyun, K. Joo-Heon, C. Hunhee, and K. Kyung-In, "Development of a mobile safety monitoring system for construction sites", Automat. Constr., vol. 18, no. 3, pp. 258-264, 2009.

[17] A. P. Wang, J. C. Chen, and P. L. Hsu, "Intelligent CAN-based Automotive Collision Avoidance warning system", In: Proc. 2004 IEEE International Conference on Networking, Sensing \& Control, March 21-23, Taipei, Taiwan, 2004.

[18] K. Tantisevi, and B. Akinci, "Automated generation of workspace requirements of mobile crane operations to support conflict detection", Automat. Constr., vol. 16, no. 3, pp. 262-276, 2007.

[19] B. Naticchia, M. Vaccarini, and A. Carbonari, "A monitoring system for real-time interference control on large construction sites", Automat. Constr., vol. 29, pp. 148-160, 2013.

[20] M. Budde, M. Busse, and M. Beigl, "Investigating the use of commodity dust sensors for the embedded measurement of particulate matter", In: Proc. $9^{\text {th }}$ International Conference on Networked Sensing Systems (INSS), Antwerp, Belgium, June 2012.

[21] R. J. Lang, "Capillary wave theory in ultrasonic field", J. Acoust. Soc. Am., vol. 34, no. 6, 1962

(C) Naticchia et al.; Licensee Bentham Open.

This is an open access article licensed under the terms of the Creative Commons Attribution Non-Commercial License (http://creativecommons.org/licenses/by-nc/3.0/g) which permits unrestricted, non-commercial use, distribution and reproduction in any medium, provided the work is properly cited. 